\title{
The Role of 18F-Flortaucipir (AV-1451) in the Diagnosis of Neurodegenerative Disorders
}

\author{
Saswata Roy ${ }^{1}$, Dipanjan Banerjee ${ }^{2,3}$, Indrajit Chatterjee ${ }^{4}$, Deepika Natarajan ${ }^{5}$, Christopher Joy Mathew ${ }^{2}$ \\ 1. General Medicine, Musgrove Park Hospital, Taunton, GBR 2. Internal Medicine, East Sussex Healthcare NHS Trust, \\ Hastings, GBR 3. Neuroscience, California Institute of Behavioral Neurosciences \& Psychology, Fairfield, USA 4. \\ General Psychiatry, Wishaw University Hospital, Hamilton, GBR 5. General Surgery, North Cumbria Integrated Care \\ (NCIC), Carlisle, GBR
}

Corresponding author: Saswata Roy, saswata@rocketmail.com

\begin{abstract}
Tau protein plays a vital role in maintaining the structural and functional integrity of the nervous system; however, hyperphosphorylation or abnormal phosphorylation of tau protein plays an essential role in the pathogenesis of several neurodegenerative disorders. The development of radioligand such as the $18 \mathrm{~F}-$ flortaucipir (AV-1451) has provided us with the opportunity to assess the underlying tau pathology in various etiologies of dementia. For the purpose of this article, we aimed to evaluate the utility of 18F-AV1451 in the differential diagnosis of various neurodegenerative disorders. We used PubMed to look for the latest, peer-reviewed, and informative articles. The scope of discussion included the role of $18 \mathrm{~F}-\mathrm{AV}-1451$ positron emission tomography (PET) to aid in the diagnosis of Alzheimer's disease (AD), frontotemporal dementia (FTD), dementia with Lewy bodies (DLB), and Parkinson's disease with dementia (PDD). We also discussed if the tau burden identified by neuroimaging correlated well with the clinical severity and identified the various challenges of 18F-AV-1451 PET. We concluded that although the role of 18F-AV-1451 seems promising in the neuroimaging of $\mathrm{AD}$, the benefit appears uncertain when it comes to the nonAlzheimer's tauopathies. More research is required to identify the off-target binding sites of $18 \mathrm{~F}-\mathrm{AV}-1451$ to determine its clinical utility in the future.
\end{abstract}

Categories: Neurology, Psychiatry, Radiology

Keywords: 18f-av-1451, alzheimer's disease, frontotemporal dementia, dementia with lewy bodies, parkinson's disease, tau

\section{Introduction And Background}

\author{
"None of us wants to be reminded that dementia is random, relentless, and frighteningly common." \\ - Laurie Graham
}

Review began 06/26/2021 Review ended 07/13/2021 Published 07/26/2021

\section{๑) Copyright 2021}

Roy et al. This is an open access article distributed under the terms of the Creative Commons Attribution License CC-BY 4.0., which permits unrestricted use, distribution, and reproduction in any medium, provided the original author and source are credited.
Worldwide, around 50 million people are affected with dementia, with 10 million new diagnoses every year. This number is projected to reach 82 million in 2030 and 152 million by 2050, a 204\% rise [1]. Etiologies of dementia are quite diverse, Alzheimer's disease $(\mathrm{AD})$ being the commonest one [2,3]. This is followed by vascular dementia (VaD), which is considered the second most common cause of dementia [4]. Other causes of dementia include frontotemporal dementia (FTD), dementia with Lewy bodies (DLB), Parkinson's disease with dementia (PDD) $[5,6]$. In both the central and peripheral nervous system, microtubule assembly (MT) is promoted by a microtubule assembly protein (MAP), also known as Tau protein. By playing a pivotal role in MT assembly and stabilization, Tau protein helps to maintain the structural and functional integrity of the nervous system [7]. However, abnormal phosphorylation of tau protein results in filamentous deposits in neurons and glial cells, contributing to the pathogenesis of various neurodegenerative disorders [7]. Such lesions have been described in $\mathrm{AD}$, and other neurodegenerative disorders popularly referred to as tauopathies [8]. 18F-flortaucipir (AV-1451) is a radiotracer widely used in positron emission tomography (PET) which shows high affinity towards tau protein deposits and used in neuroimaging of neurodegenerative disorders involving tau protein abnormalities [9]. In this review, we aim to briefly evaluate and summarize the role of 18F-AV-1451 PET imaging in the diagnosis of various common etiologies of dementia.

\section{Review}

\section{Method}

For the purpose of this literature review, PubMed was searched extensively with appropriate keywords mentioned, to look for relevant articles. We included the studies conducted within the last eight years, specifically on humans. A total of 31 studies were included after considering the citations, year of publication, subject population, and statistical significance. Older studies or studies conducted on other species were not included. Data was collected ethically and legally. 


\section{Cureus}

\section{Discussion}

Tau Protein: A Brief Introduction

Tau protein is also known as microtubule assembly protein (MAP) which helps maintain the structural and functional integrity of neurons by promoting and stabilizing microtubules [10]. The gene responsible for the synthesis of Tau protein is located on chromosome 17 and contains 16 exons [7]. Out of these, exons 9-12 code for four microtubule-binding motifs, and alternative splicing of exon 10 leads to the formation of tau isoforms with three (3R) or four repeat (4R) domains [7]. In total, there are six tau isoforms present in the adult brain [7]. Posttranslational modification involving phosphorylation plays a significant role in diversifying the tau isoforms [11]. This process of phosphorylation is carefully controlled by the activity of tau kinase and phosphatase [11]. Disruption of this equilibrium leads to abnormal or hyperphosphorylation of tau protein resulting in the accumulation of tau protein aggregates which play an important role in the pathogenesis of various etiologies of dementia [11].

\section{Alzheimer's Disease: Dual Pathogenesis}

Alzheimer's disease (AD) is the commonest form of dementia, with 6.2 million affected in the USA, a number that is projected to increase to 13.8 million by 2060 [5]. The underlying pathology in $\mathrm{AD}$ involves the formation of extracellular amyloid plaques, and intracellular neurofibrillary lesions (NFL) made up of abnormally phosphorylated tau protein [12]. A study done on AD and progressive supranuclear palsy (PSP) patients using 18F-AV-1451 PET imaging established increased 18F-AV-1451 retention in the hippocampus and frontal, occipital, and temporoparietal cortices of AD patients when compared to PSP subjects [13]. The PSP group, on the other hand, showed increased retention in the region of the midbrain when compared to $\mathrm{AD}$ patients [13]. A study comparing antemortem PET findings and post mortem autopsy findings found out that there was a good correlation between areas of $18 \mathrm{~F}-\mathrm{AV}-1451$ retention and neurofibrillary lesion distribution in $\mathrm{AD}$ patients [14]. The group with non-Alzheimer's tauopathies and non-tau pathologies showed lower retention of $18 \mathrm{~F}-\mathrm{AV}-1451$ compared to the $\mathrm{AD}$ group but higher when compared to the control population [14]. While analyzing the Braak stages, it was also established that patients with advanced Braak stages showed higher tracer retention while the patients with lower Braak stages failed to show increased uptake compared to the control population [14]. Comparing tau imaging with 18F-AV-1451 PET and betaamyloid imaging with PiB-PET, it has been suggested that the regional distribution of $18 \mathrm{~F}-\mathrm{AV}-1451$ retention shows a stronger association with different clinical variants of $A D$ than amyloid distribution [15]. For example, patients with posterior cortical atrophy (PCA) showed higher 18F-AV-1451 uptake in the posterior fossa while PiB binding was elevated across the whole neocortex [15]. Similarly, patients with predominant memory issues showed higher 18F-AV-1451 retention in the medial temporal and lateral temporoparietal areas [15]. Similar findings were also shared by other studies [16]. The relevant studies are summarized below in Table 1.

\begin{tabular}{|c|c|c|c|}
\hline Author & $\begin{array}{l}\text { Imaging } \\
\text { modality }\end{array}$ & Subjects & Summary of findings \\
\hline $\begin{array}{l}\text { Passamonti et } \\
\text { al. [13] }\end{array}$ & $\begin{array}{l}\text { 18F-AV-1451 } \\
\text { PET }\end{array}$ & 15 AD, 19 PSP, 13 HC & $\begin{array}{l}\text { AD group showed higher retention in the hippocampus and frontal, occipital, and } \\
\text { temporoparietal cortices, while PSP patients showed increased retention in the region } \\
\text { of the midbrain. }\end{array}$ \\
\hline $\begin{array}{l}\text { Soleimani- } \\
\text { Meigooni et } \\
\text { al. [14] }\end{array}$ & $\begin{array}{l}\text { 18F-AV-1451 } \\
\text { PET }\end{array}$ & $\begin{array}{l}8 \mathrm{AD}, 9 \text { non-Alzheimer } \\
\text { tauopathies and } 3 \\
\text { non-tau FTD }\end{array}$ & $\begin{array}{l}\text { Good correlation between areas of } 18 \mathrm{~F}-\mathrm{AV}-1451 \text { retention and neurofibrillary lesion } \\
\text { distribution in post-mortem AD patients, also higher amount of retention was seen in } \\
\text { more advanced Braak stages. }\end{array}$ \\
\hline $\begin{array}{l}\text { Ossenkoppele } \\
\text { et al. [15] }\end{array}$ & $\begin{array}{l}\text { 18F-AV-1451 } \\
\text { PET, PiB-PET, } \\
\text { FDG-PET }\end{array}$ & $20 \mathrm{AD}, 15 \mathrm{HC}$ & $\begin{array}{l}\text { Compared to other radiotracers, the regional distribution of } 18 \mathrm{~F}-\mathrm{AV}-1451 \text { retention } \\
\text { correlates well with the different regions of the brain affected in various variants of } \\
\text { AD. }\end{array}$ \\
\hline $\begin{array}{l}\text { Hoenig et al. } \\
\text { [16] }\end{array}$ & $\begin{array}{l}\text { 18F-AV-1451 } \\
\text { PET }\end{array}$ & $22 \mathrm{AD}, 26 \mathrm{HC}$ & $\begin{array}{l}\text { Higher uptake was associated with higher Braak stages, regional uptake correlated } \\
\text { well with functional networks involved. }\end{array}$ \\
\hline $\begin{array}{l}\text { AD: Alzheimer's } \\
\text { tomography; FD } \\
\text { tomography. }\end{array}$ & PET: fluorine- & $\begin{array}{l}\text { temporal dementia; } \\
\text { uorodeoxyglucose } p\end{array}$ & $\begin{array}{l}\text { : progressive supranuclear palsy; HC: healthy controls; PET: positron emission } \\
\text { tron emission imaging; PiB-PET: Pittsburgh compound B positron emission }\end{array}$ \\
\hline
\end{tabular}

Frontotemporal Dementia (FTD)

A familial form of FTD was identified in 1994 linked to the MAPT gene on chromosome 17, which was later 
named frontotemporal dementia, and parkinsonism linked to chromosome 17 (FTDP-17) due to its similar clinical, neurological, and genetic profile [7,17]. A study conducted on 45 patients of FTD including various variants and 53 control subjects showed the following: nonfluent variant primary progressive aphasia (nfvPPA) patients showed increased 18F-AV-1451 binding in the left inferior frontal gyrus (asymmetrically, more than right hemisphere), patients with corticobasal syndrome (CBS) showed raised binding in frontal white matter [18]. Increased 18F-AV-1451 retention was noticed in bilateral temporal lobes in carriers of MAPT mutation, and frontotemporal binding was observed in $50 \%$ of the behavioral variant frontotemporal dementia (bvFTD) patients [18]. Another study by Bevan-Jones et al. showed markedly raised non-

displaceable binding potential (BPND) of 18F-AV-1451, especially in the anterior temporal lobes and ventral anterior cingulate cortex of patients with MAPT mutations compared to the healthy control subjects [19]. Smith et al. observed increased 18F-AV-1451 retention in the regions of the hippocampus and adjacent temporal lobe in patients with MAPT mutations [20]. This study also observed the extent of 18F-AV-1451 retention to be associated with the clinical severity of the disease observed [20]. They also performed a postmortem analysis in a patient and found out that the areas which showed increased antemortem 18F-AV-1451 binding also tested positive for tau pathologies post-mortem and even tested negative amyloid staining [20]. Elevated BPND was observed in patients with semantic dementia in the regions of the temporal cortex, insula, and fusiform gyrus, which correlates well with the regions known to be affected in this variant [21]. This study displayed $86 \%$ sensitivity and $100 \%$ specificity when differentiating between patients of semantic dementia and the control subjects [21]. The findings of these studies are summarized in Table 2.

\begin{tabular}{|c|c|c|c|}
\hline Author & $\begin{array}{l}\text { Imaging } \\
\text { modality }\end{array}$ & Subjects & Summary of findings \\
\hline $\begin{array}{l}\text { Tsai et } \\
\text { al. [18] }\end{array}$ & $\begin{array}{l}\text { 18F-AV-1451 } \\
\text { PET, PiB- } \\
\text { PET, MRI }\end{array}$ & $\begin{array}{l}45 \text { FTD (11 nfvPPA, } 10 \\
\text { CBS, } 10 \text { bvFTD, } 2 \text { svPPA, } \\
6 \text { MAPT mutants, } 5 \\
\text { C9ORF72 mutants, } 1 \text { GRN } \\
\text { mutant), } 53 \text { HC }\end{array}$ & $\begin{array}{l}\text { nfvPPA: Increased AV-1451 binding in the left inferior frontal gyrus compared to the right } \\
\text { hemisphere, CBS: Higher } 18 \mathrm{~F}-\mathrm{AV}-1451 \text { binding in the frontal white matter, bvFTD: Five out } \\
\text { of } 10 \text { patients showed increased } 18 \mathrm{~F}-\mathrm{AV}-1451 \text { retention in the frontotemporal region, MAPT } \\
\text { carriers: Higher } 18 \mathrm{~F}-\mathrm{AV}-1451 \text { binding in the bilateral temporal lobes compared to controls. }\end{array}$ \\
\hline $\begin{array}{l}\text { Bevan } \\
\text { Jones } \\
\text { et al. } \\
{[19]}\end{array}$ & $\begin{array}{l}\text { 18F-AV-1451 } \\
\text { PET }\end{array}$ & $\begin{array}{l}\text { A case of familial FTD with } \\
\text { MAPT mutation, } 12 \mathrm{HC}\end{array}$ & $\begin{array}{l}\text { Significantly increased BPND in MAPT carrier especially in the anterior temporal lobes and } \\
\text { ventral anterior cingulate cortex compared to the control subjects. }\end{array}$ \\
\hline $\begin{array}{l}\text { Smith } \\
\text { et al. } \\
{[20]}\end{array}$ & $\begin{array}{l}18 \mathrm{~F}-\mathrm{AV}-1451 \\
\text { PET, } 18 \mathrm{~F}- \\
\text { flutemetamol } \\
\text { PET, FDG- } \\
\text { PET }\end{array}$ & $\begin{array}{l}3 \text { MAPT mutants, } 4 \text { HC, } 5 \\
\text { AD }\end{array}$ & $\begin{array}{l}\text { Raised } 18 \mathrm{~F}-\mathrm{AV}-1451 \text { binding in the regions of the hippocampus and adjacent temporal lobe } \\
\text { in MAPT mutants, widespread retention was seen in the patient with higher clinical severity. }\end{array}$ \\
\hline $\begin{array}{l}\text { Bevan- } \\
\text { Jones } \\
\text { et al. } \\
{[21]}\end{array}$ & $\begin{array}{l}\text { PET using } \\
\text { 11C-PK- } \\
\text { 11195, 18F- } \\
\text { AV-1451 }\end{array}$ & $\begin{array}{l}31 \text { FTD (10 bvFTD, } 11 \\
\text { svPPA, } 10 \text { nfvPPA), } 29 \text { HC }\end{array}$ & $\begin{array}{l}\text { Markedly raised BPND in semantic dementia in the regions of the temporal cortex, insula, } \\
\text { and fusiform gyrus, also found a good correlation between neuroinflammation and tau } \\
\text { retention. }\end{array}$ \\
\hline $\begin{array}{l}\text { AD: Alzhe } \\
\text { tomograp } \\
\text { tomograp } \\
\text { syndrome } \\
\text { tau; C9OF }\end{array}$ & $\begin{array}{l}\text { limer's disease; } \\
\text { hyy; FDG-PET: fl } \\
\text { hy; bvFTD: beh } \\
\text { e; svPPA: semar } \\
\text { RF72: chromoso }\end{array}$ & $\begin{array}{l}\text { FTD: frontotemporal dement } \\
\text { luorine-18-fluorodeoxyglucos } \\
\text { lavioral variant of frontotempo } \\
\text { tic variant primary progressiv } \\
\text { ome } 9 \text { open reading frame } 72 \text {; }\end{array}$ & $\begin{array}{l}\text { ontotemporal dementia } \\
\text { ia; PSP: progressive supranuclear palsy; HC: healthy controls; PET: positron emission } \\
\text { e positron emission imaging; PiB-PET: Pittsburgh compound B positron emission } \\
\text { oral dementia; nfvPPA: nonfluent variant primary progressive aphasia; CBS: corticobasal } \\
\text { ve aphasia; BPND: non-displaceable binding potential; MAPT: microtubule assembly protein } \\
\text {; GRN: progranulin gene. }\end{array}$ \\
\hline
\end{tabular}

Dementia with Lewy Bodies (DLB)

DLB is characterized by a significantly lower uptake of $18 \mathrm{~F}-\mathrm{AV}$-1451, especially in the medial temporal lobe compared to $\mathrm{AD}$ [22]. However, increased retention of $18 \mathrm{~F}-\mathrm{AV}-1451$ was seen in the posterior temporoparietal and occipital cortex of the DLB group compared to the control group which correlated well with the PiB retention, suggesting an atypical pattern of tau pathology in DLB [22]. Another study conducted by Gomperts et al. on DLB, PDD, and PD without dementia patients showed increased 18F-AV-1451 retention in both DLB and PDD patients compared to the control groups and PD without dementia patients [23]. Although the tau burden was much lower than $\mathrm{AD}$, the topographical distribution of high tracer retention mimicked that of the AD [23]. The extent of $18 \mathrm{~F}-\mathrm{AV}-1451$ uptake was also found to correlate well with the clinical severity of cognitive dysfunction as measured by mini-mental state examination (MMSE) [23,24]. Increased parietal $18 \mathrm{~F}-\mathrm{AV}-1451$ retention has also been recorded in DLB patients and this was linked to the abnormality of executive functions in these patients [25]. These findings are summarized below in Table 3. 


\section{Cureus}

\begin{tabular}{|c|c|c|c|}
\hline Author & $\begin{array}{l}\text { Imaging } \\
\text { modality }\end{array}$ & Subjects & Summary of findings \\
\hline $\begin{array}{l}\text { Kantarci } \\
\text { et al. [22] }\end{array}$ & $\begin{array}{l}\text { 18F-AV- } \\
\text { 1451, PiB } \\
\text { PET }\end{array}$ & 19 DLB, 19 AD, 95 HC & $\begin{array}{l}18 \mathrm{~F}-\mathrm{AV}-1451 \text { retention in DLB is lesser compared to } \mathrm{AD} \text {, but higher in the posterior } \\
\text { temporoparietal and occipital cortex compared to the control group. }\end{array}$ \\
\hline $\begin{array}{l}\text { Gomperts } \\
\text { et al. [23] }\end{array}$ & $\begin{array}{l}\text { 18F-AV- } \\
\text { 1451, PiB } \\
\text { PET }\end{array}$ & $\begin{array}{l}7 \mathrm{DLB}, 8 \mathrm{PDD}, 9 \mathrm{PD} \\
\text { without dementia, } 29 \mathrm{HC}\end{array}$ & $\begin{array}{l}\text { Markedly raised } 18 \mathrm{~F}-\mathrm{AV}-1451 \text { retention in both } \mathrm{DLB} \text { and PDD compared to the healthy } \\
\text { controls, increased tau burden correlates well with the clinical severity. }\end{array}$ \\
\hline $\begin{array}{l}\text { Smith et } \\
\text { al. [25] }\end{array}$ & $\begin{array}{l}\text { 18F-AV- } \\
1451 \text { PET, } \\
\text { MRI }\end{array}$ & without dementia, $44 \mathrm{HC}$ & $\begin{array}{l}\text { Raised parietal } 18 \mathrm{~F}-\mathrm{AV}-1451 \text { binding in DLB patients, which was linked to abnormality in } \\
\text { executive functions in patients. }\end{array}$ \\
\hline \multicolumn{4}{|c|}{ TABLE 3: Summary of findings in dementia with Lewy bodies } \\
\hline \multicolumn{4}{|c|}{ 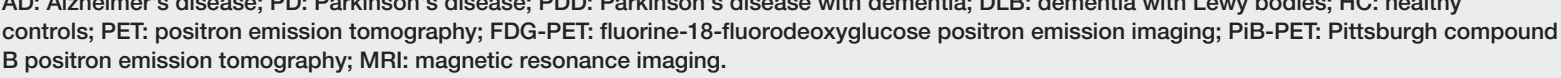 } \\
\hline
\end{tabular}

Parkinson's Disease (PD)

PDD patients have shown raised 18F-AV-1451 binding in the inferior temporal gyrus and precuneus compared to the control population suggesting a role of tau pathology [23]. The degree of tau burden, although remarkably less than that of $\mathrm{AD}$, has also been shown to correlate well with the clinical severity of the disease [23]. Another study demonstrated reduced 18F-AV-1451 retention in the substantia nigra in PDD [25]. This was also found to be associated with worsening motor functions [25]. The total nigral 18F-AV-1451 volume of distribution was measured to be $30 \%$ lower in patients with idiopathic PD compared to the healthy control population [26]. However, no association has been found between the side with dominant symptoms and the contralateral nigral volume of distribution [26]. Another study conducted on PSP and PD patients showed a remarkably decreased nigral standardized uptake value ratio (SUVr) compared to the healthy controls [27]. However, no remarkable difference was observed in terms of nigral SUVr between PD and PSP groups [27]. Researchers observed raised subcortical 18F-AV-1451 uptake in PD and PSP patients but did not find any correlation with the severity of motor symptoms [14,28]. Tau pathology has also been found to be uncommon in patients with PD and mild cognitive impairment [29]. The findings of these studies are summarized below in Table 4 . 


\section{Cureus}

\begin{tabular}{|c|c|c|c|}
\hline Author & Imaging modality & Subjects & Summary of findings \\
\hline $\begin{array}{l}\text { Gomperts } \\
\text { et al. [23] }\end{array}$ & $\begin{array}{l}\text { 18F-AV-1451, PiB } \\
\text { PET }\end{array}$ & $\begin{array}{l}7 \text { DLB, } 8 \text { PDD, } 9 \text { PD } \\
\text { without dementia, } 29 \\
\text { HC }\end{array}$ & $\begin{array}{l}\text { Although less than AD, } 18 \mathrm{~F}-\mathrm{AV}-1451 \text { retention is higher in PDD group compared to the } \\
\text { control group. }\end{array}$ \\
\hline $\begin{array}{l}\text { Smith et } \\
\text { al. [25] }\end{array}$ & $\begin{array}{l}\text { 18F-AV-1451 PET, } \\
\text { MRI }\end{array}$ & $\begin{array}{l}6 \text { DLB, } 18 \text { PDD, } 11 \text { PD } \\
\text { without dementia, } 44 \\
\text { HC }\end{array}$ & Reduced 18F-AV-1451 retention was seen in the substantia nigra of PDD patients. \\
\hline $\begin{array}{l}\text { Hansen } \\
\text { et al. [26] }\end{array}$ & $\begin{array}{l}(123) I-F P-C I T \\
\text { SPECT, 18F-AV- } \\
1451 \text { PET }\end{array}$ & $\begin{array}{l}17 \text { idiopathic PD, } 16 \\
\text { HC }\end{array}$ & $\begin{array}{l}\text { The nigral } 18 \mathrm{~F}-\mathrm{AV}-1451 \text { volume of distribution was significantly reduced in idiopathic } \\
\text { PD patients than in the control group. }\end{array}$ \\
\hline $\begin{array}{l}\text { Coakeley } \\
\text { et al. [27] }\end{array}$ & 18F-AV-1451 PET & $\begin{array}{l}12 \text { patients including } \\
\text { PD and PSP, } 15 \mathrm{HC}\end{array}$ & $\begin{array}{l}\text { Significantly decreased nigral } 18 \mathrm{~F}-\mathrm{AV}-1451 \text { uptake in both PD and PSP patients } \\
\text { compared to the control groups, no remarkable difference observed between PD and } \\
\text { PSP patients. }\end{array}$ \\
\hline $\begin{array}{l}\text { Cho et al. } \\
\text { [28] }\end{array}$ & 18F-AV-1451 PET & 14 PSP, 15 PD, 15 HC & $\begin{array}{l}\text { Raised sub-cortical 18F-AV-1451 retention was seen in PD and PSP patients and } \\
\text { reduced nigral 18F-AV-1451 volume of distribution was noticed in PD patients. }\end{array}$ \\
\hline
\end{tabular}

\section{TABLE 4: Summary of findings in Parkinson's disease}

PD: Parkinson's disease; PDD: Parkinson's disease with dementia; DLB: dementia with Lewy bodies; PSP: progressive supranuclear palsy; HC: healthy controls; PET: positron emission tomography; FDG-PET: fluorine-18-fluorodeoxyglucose positron emission imaging; PiB-PET: Pittsburgh compound B positron emission tomography; MRI: magnetic resonance imaging; [123I]FP- CIT-SPECT: lodine 123-radiolabeled 2 $\beta$-carbomethoxy$3 \beta$-(4-iodophenyl)-N-(3-fluoropropyl) nortropane single-photon emission tomography.

Pitfalls of $18 F-A V-1451$

18F-AV-1451, although showing promise in detecting advanced stages of AD with higher Braak stages, such results were not replicated in patients with earlier Braak stages compared to the control population [14]. This might indicate reduced affinity of $18 \mathrm{~F}-\mathrm{AV}-1451$ towards less mature tau formations [30]. The role of $18 \mathrm{~F}-\mathrm{AV}-$ 1451 in detecting non-Alzheimer's tauopathies has been doubted by several researchers [14,21]. This has been partly explained by the finding that 18F-AV-1451 showed more affinity towards paired helical filaments rather than straight filaments found in abundance in non-Alzheimer's tauopathies [31]. Histologically AD is characterized by mixed 3R and $4 \mathrm{R}$ tau deposits, which are more actively recognized by $18 \mathrm{~F}-\mathrm{AV}-1451$ than disorders that are mainly known to have an accumulation of either 3R or 4R [30]. The inconsistency of findings between in-vivo and post-mortem subjects also popularized the idea of off-target binding for 18FAV-1451 [21]. Such off-target sites were observed by studies in vessels, melanin, and neuromelanincontaining tissues $[30,31]$. Researchers agree that more knowledge and recognition of such off-target sites may play a vital role in determining the clinical utility of 18F-AV-1451 [30].

\section{Conclusions}

After a detailed review, we conclude that 18F-AV-1451 shows promise in demonstrating the underlying tau pathology in $\mathrm{AD}$, particularly in advanced stages where it correlates well with higher Braak stages. However, its role in non-Alzheimer's tauopathies remains uncertain due to the observation that it shows less affinity towards straight filaments, which plays an important role in such neurodegenerative disorders. 18F-AV-1451 may be one of the first biomarkers to provide neuroimaging of the nigral pathology in PD, but more research is required both in-vivo and post-mortem for the recognition of several off-target binding sites, which will also play a significant role in assessing the clinical utility of 18F-AV-1451 PET.

\section{Additional Information \\ Disclosures}

Conflicts of interest: In compliance with the ICMJE uniform disclosure form, all authors declare the following: Payment/services info: All authors have declared that no financial support was received from any organization for the submitted work. Financial relationships: All authors have declared that they have no financial relationships at present or within the previous three years with any organizations that might have an interest in the submitted work. Other relationships: All authors have declared that there are no other relationships or activities that could appear to have influenced the submitted work.

\section{References}

1. Dementia. (2021). Accessed: June 12, 2021: https://www.who.int/news-room/fact-sheets/detail/dementia. 
2. Lane CA, Hardy J, Schott JM: Alzheimer's disease. Eur J Neurol. 2018, 25:59-70. 10.1111/ene.13439

3. Fleming R, Zeisel J, Bennett K: World Alzheimer Report 2020 - Design, Dignity, Dementia: DementiaRelated Design and the Built Environment, Volume 1. Alzheimer's Disease International, London, England; 2020.

4. Hébert R, Brayne C: Epidemiology of vascular dementia. Neuroepidemiology. 1995, 14:240-257. 10.1159/000109800

5. 2021 Alzheimer's disease facts and figures. Alzheimers Dement. 2021, 17:327-406. 10.1002/alz.12328

6. Banerjee D, Muralidharan A, Hakim Mohammed AR, Malik BH: Neuroimaging in dementia: a brief review . Cureus. 2020, 12:e8682. 10.7759/cureus.8682

7. Tolnay M, Probst A: The neuropathological spectrum of neurodegenerative tauopathies . IUBMB Life. 2003, 55:299-305. 10.1080/1521654032000114348

8. Sergeant N, Delacourte A, Buée L: Tau protein as a differential biomarker of tauopathies . Biochim Biophys Acta. 2005, 1739:179-197. 10.1016/j.bbadis.2004.06.020

9. Drake LR, Pham JM, Desmond TJ, et al.: Identification of AV-1451 as a weak, nonselective inhibitor of monoamine oxidase. ACS Chem Neurosci. 2019, 10:3839-3846. 10.1021/acschemneuro.9b00326

10. Buée L, Bussière T, Buée-Scherrer V, Delacourte A, Hof PR: Tau protein isoforms, phosphorylation and role in neurodegenerative disorders. Brain Res Rev. 2000, 33:95-130. 10.1016/S0165-0173(00)00019-9

11. Martin L, Latypova X, Wilson CM, Magnaudeix A, Perrin ML, Yardin C, Terro F: Tau protein kinases: involvement in Alzheimer's disease. Ageing Res Rev. 2013, 12:289-309. 10.1016/j.arr.2012.06.003

12. Hardy J, Selkoe DJ: The amyloid hypothesis of Alzheimer's disease: progress and problems on the road to therapeutics. Science. 2002, 297:353-356. 10.1126/science.1072994

13. Passamonti L, Vázquez Rodríguez P, Hong YT, et al.: 18F-AV-1451 positron emission tomography in Alzheimer's disease and progressive supranuclear palsy. Brain. 2017, 140:781-791. 10.1093/brain/aww340

14. Soleimani-Meigooni DN, Iaccarino L, La Joie R, et al.: 18F-flortaucipir PET to autopsy comparisons in Alzheimer's disease and other neurodegenerative diseases. Brain. 2020, 143:3477-3494. 10.1093/brain/awaa276

15. Ossenkoppele R, Schonhaut DR, Schöll M, et al.: Tau PET patterns mirror clinical and neuroanatomical variability in Alzheimer's disease. Brain. 2016, 139:1551-1567. 10.1093/brain/aww027

16. Hoenig MC, Bischof GN, Seemiller J, et al.: Networks of tau distribution in Alzheimer's disease . Brain. 2018, 141:568-581. 10.1093/brain/awx353

17. Forrest SL, Kril JJ, Stevens CH, et al.: Retiring the term FTDP-17 as MAPT mutations are genetic forms of sporadic frontotemporal tauopathies. Brain. 2018, 141:521-534. 10.1093/brain/awx328

18. Tsai RM, Bejanin A, Lesman-Segev O, et al.: 18F-flortaucipir (AV-1451) tau PET in frontotemporal dementia syndromes. Alzheimers Res Ther. 2019, 11:13. 10.1186/s13195-019-0470-7

19. Bevan Jones WR, Cope TE, Passamonti L, et al.: [18F]AV-1451 PET in behavioral variant frontotemporal dementia due to MAPT mutation. Ann Clin Transl Neurol. 2016, 3:940-947. 10.1002/acn3.366

20. Smith R, Puschmann A, Schöll M, et al.: 18F-AV-1451 tau PET imaging correlates strongly with tau neuropathology in MAPT mutation carriers. Brain. 2016, 139:2372-2379. 10.1093/brain/aww163

21. Bevan-Jones WR, Cope TE, Jones PS, et al.: [18F]AV-1451 binding in vivo mirrors the expected distribution of TDP-43 pathology in the semantic variant of primary progressive aphasia. J Neurol Neurosurg Psychiatry. 2018, 89:1032-1037. 10.1136/jnnp-2017-316402

22. Kantarci K, Lowe VJ, Boeve BF, et al.: AV-1451 tau and $\beta$-amyloid positron emission tomography imaging in dementia with Lewy bodies. Ann Neurol. 2017, 81:58-67. 10.1002/ana.24825

23. Gomperts SN, Locascio JJ, Makaretz SJ, et al.: Tau positron emission tomographic imaging in the Lewy body diseases. JAMA Neurol. 2016, 73:1334-1341. 10.1001/jamaneurol.2016.3338

24. Saha A, Banerjee D: Neuroimaging in dementia with Lewy bodies . Cureus. 2021, 13:e15694. 10.7759/cureus.15694

25. Smith R, Schöll M, Londos E, Ohlsson T, Hansson O: 18F-AV-1451 in Parkinson's disease with and without dementia and in dementia with Lewy bodies. Sci Rep. 2018, 8:4717. 10.1038/s41598-018-23041-X

26. Hansen AK, Knudsen K, Lillethorup TP, et al.: In vivo imaging of neuromelanin in Parkinson's disease using 18F-AV-1451 PET. Brain. 2016, 139:2039-2049. 10.1093/brain/aww098

27. Coakeley S, Cho SS, Koshimori Y, et al.: [18F]AV-1451 binding to neuromelanin in the substantia nigra in PD and PSP. Brain Struct Funct. 2018, 223:589-595. 10.1007/s00429-017-1507-y

28. Cho H, Choi JY, Hwang MS, Lee SH, Ryu YH, Lee MS, Lyoo CH: Subcortical 18 F-AV-1451 binding patterns in progressive supranuclear palsy. Mov Disord. 2017, 32:134-140. 10.1002/mds.26844

29. Hansen AK, Damholdt MF, Fedorova TD, et al.: In Vivo cortical tau in Parkinson's disease using 18F-AV-1451 positron emission tomography. Mov Disord. 2017, 32:922-927. 10.1002/mds.26961

30. Lowe VJ, Curran G, Fang P, et al.: An autoradiographic evaluation of AV-1451 Tau PET in dementia . Acta Neuropathol Commun. 2016, 4:58. 10.1186/s40478-016-0315-6

31. Marquié M, Normandin MD, Vanderburg CR, et al.: Validating novel tau positron emission tomography tracer [F-18]-AV-1451 (T807) on postmortem brain tissue. Ann Neurol. 2015, 78:787-800. 10.1002/ana. 24517 